\title{
The effects of the acoustic properties of second language vowel production on pronunciation evaluation
}

Chris Sheppard

Faculty of Science and Engineering, Waseda University, Japan

https://doi.org/10.36505/ExLing-2008/02/0051/000110

\begin{abstract}
This study examines the acoustic characteristics which native speakers use as cues when judging speech samples. 17 words produced by 98 (15 native speakers and 83 Japanese learners of English) were collected and evaluated. Following this, the first three formants for each vowel produced were measured and used as independent variables in stepwise multiple regression analyses to explain variance in the evaluations. The results demonstrated that the formants did explain variance in evaluation in many but not all of the words $\left(\mathrm{r}^{2}=0.0\right.$ to .36$)$.
\end{abstract}

Key words: vowels, pronunciation, evaluation, formants

\section{Introduction}

Studies have been using native speaker evaluation of words, sentences and passages to determine factors behind the successful second language pronunciation for more than thirty years (e.g. Oyama, 1976; Piske, 2001; Purcell and Suter, 1980; Sheppard, Hayashi and Ohmori, 2007 just to name a few.) As yet, however, there has been little examination of which acoustic properties of the pronunciation the native speakers were actually evaluating.

Munro and Derwing (1995) have determined that native speaker evaluations were being influenced by suprasegmental over segmental features of learner speech and (Wayland, 1997), analyzing production acoustically, found that the both fundamental frequency and the vowel formants predicted evaluations of English speakers production on non-native Thai words. This study attempts to determine which, if any, of the acoustic qualities of non-native English vowel production by Japanese speakers influence native speaker evaluations

\section{Method}

\section{Participants}

83 Japanese native speaking volunteers who were studying English were recruited from two universities. Some participants who had attained exceptional levels of pronunciation were invited to participate in the study by the researcher. Another 15 native speakers of American varieties of English took part in the study.

ExLing 2008: Proceedings of 2nd Tutorial and Research Workshop on Experimental Linguistics, 25-27 August 2008, Athens, Greece 


\section{Instruments and procedure}

The stimulus words consisted of 26 printed words, 12 pictures, 8 sentences, one paragraph and a question and answer session on a topic selected by the participants. For this study, 17 of the printed words containing vowels (but not dipthongs) were selected for analysis.

The 17 words selected for this study were church, happy, shoes, music, green, insect, fix, goodbye, opinion, nation, open, husband, young, discussion, ask, drink and thoughtful. These represented 10 vowels.

The speech samples were elicited in a studio and recorded at $48,000 \mathrm{kHz}$ using a Sony DAT and a condensing microphone. The samples were presented on a power point slide. After the instructions were given to the participants, they were required to pronounce each word and then click the mouse button to the next slide. There was one practice slide.

\section{Analysis}

After uploading and editing the recordings, the 1666 (17 words X 98 participants) samples were presented though Superlab 4.0 to two Native English speakers. Both were teachers with extensive experience with Japanese learners. The pronunciation of each word was rated on a five point scale based on 'how good the pronunciation was'. The Interrater reliability was high relatively at .82 .

Next, an acoustic analysis of the vowels was undertaken. This was done by measuring the first three formants of each of the 1666 samples using a Praat script. Next, the formants were entered into a stepwise linear multiple regression analysis with the evaluation of the word as the dependant variable.

\section{Results and discussion}

Figure one below describes the mean formants for both Japanese speakers (JS) and Native speakers (NS). Comparing the formants of each word with ttests, we find that Japanese production differs significantly $(p<.05)$ from that of native production in the first formant for church, green, ask and thoughtful, and insect and fix for the second formant. The JS speaker production significantly differs from NS on both formants for the words husband, drink, young, and music.

The results of the multiple regression analyses are summarized on table 1 . They demonstrate that the first three vowel formants accounted for between an insignificant amount of variance in evaluation, to a maximum of $36 \%$. 


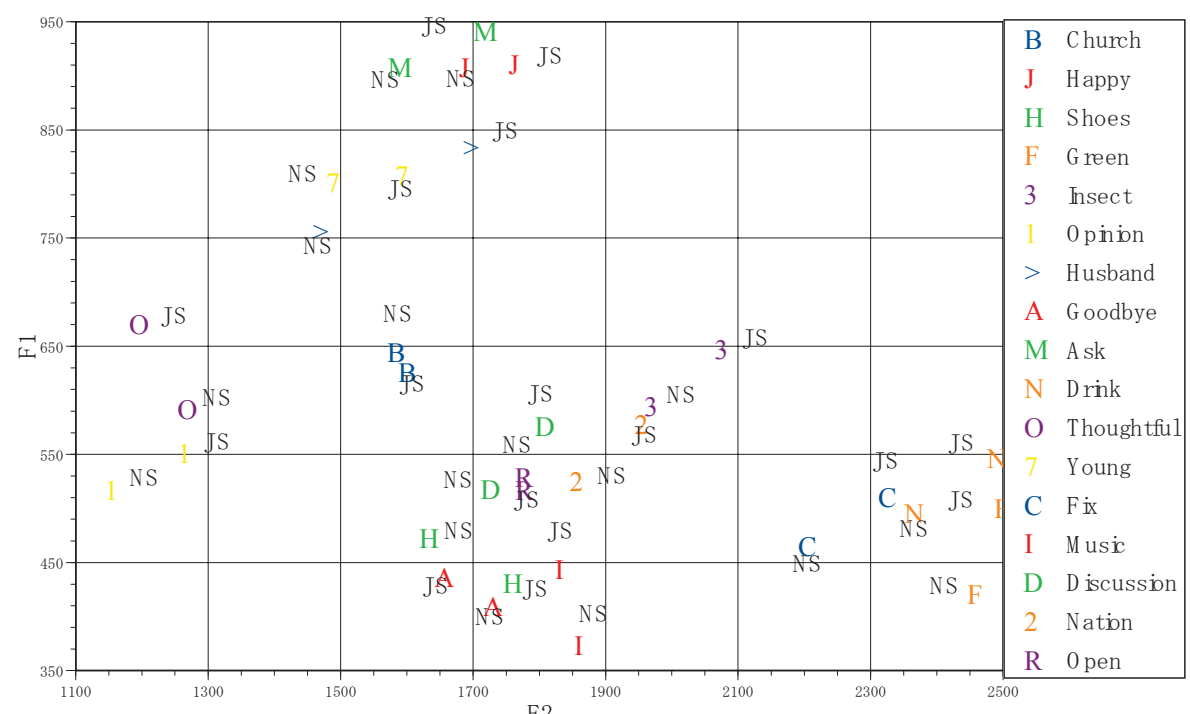

Figure 1. The mean first and second formants of vowels for JS and NS.

Table 1. The results of the step-wise regression analysis for F1, F2 and F3.

\begin{tabular}{|l|l|l|l|l|}
\hline \multirow{2}{*}{ Vowel } & \multirow{4}{*}{ Item } & \multicolumn{3}{l}{$\mathrm{r}^{2}$} \\
\cline { 3 - 5 } & & F1 & F2 & F3 \\
\hline $\mathrm{i}$ & Green & - & - & - \\
\hline $\mathrm{i}$ & Drink & - & - & - \\
\hline $\mathrm{I}$ & Fix & 0.14 & 0.22 & - \\
\hline $\mathrm{e}$ & Insect & 0.03 & 0.25 & - \\
\hline $\mathrm{e} r$ & Church & 0.20 & - & - \\
\hline $\mathrm{ae}$ & Happy & - & 0.09 & 0.04 \\
\hline $\mathrm{ae}$ & Ask & - & 0.07 & - \\
\hline $\mathrm{a}$ & Discussion & 0.08 & 0.17 & - \\
\hline $\mathrm{a}$ & Young & - & - & - \\
\hline $\mathrm{a}$ & Husband & 0.14 & - & - \\
\hline or & Thoughtful & 0.17 & - & - \\
\hline $\mathrm{u}$ & Goodbye & - & 0.09 & 0.05 \\
\hline $\mathrm{u}$ & Shoes & - & 0.23 & - \\
\hline $\mathrm{u}$ & Music & 0.04 & 0.13 & - \\
\hline schwa & Opinion & - & 0.07 & - \\
\hline schwa & Nation & - & 0.07 & - \\
\hline schwa & Open & - & 0.08 & 0.04 \\
\hline
\end{tabular}


Thus the first conclusion we can draw from this study is that Native Speaker use F1 and F2 to evaluate pronunciation of vocabulary. This result replicates that of Wayland (1997) but not of Munro and Derwing (1995) who found that surprasegmentals rather the segmental characteristics were being evaluated. However, this result was not gained as a result of an acoustic analysis. Also, the object of evaluation was lengths of multiple words rather than single words.

A second point which requires explanation is the variation in the contribution F1 and F2 had to the evaluation. Firstly, the contribution of the formants was less in multi-syllable words. The makes sense as the longer words have more objects of evaluation. Secondly, the variability in evaluation could have been due to L1 influence or L2 developmental processes or even due to the phonetic environment of the vowel.

\section{Conclusion}

This study has demonstrated that variation in the F1 and F2 of vowels in single words can predict the evaluation of those words. However, there is considerable variation in the evaluations which needs to be explained in further research. In addition, the implications for this and the teaching of pronunciation need to be investigated.

\section{Acknowledgements}

This work was funded in part by the grant-in-Aid for Scientific Research (C), "Research on the Acquisition Process of Second Language Pronunciation", no. 16520357 from JSPS

\section{References}

Munro M. J. and Derwing T. M. 1995. Foreign Accent, Comprehensibility, and Intelligibility in the Speech of Second Language Learners. Language Learning 45, 73-97.

Oyama, S. 1976. A sensitive period for the acquisition of a nonnative phonological system. Journal of Psycholinguistic Research 5, 261-283.

Piske, T., MacKay, I. R. A., and Flege, J. E. 2001. Factors affecting degree of foreign accent in an L2: A review. Journal of Phonetics 29, 191-215.

Purcell, E. T., and Suter, R. W. 1980. Predictors of pronunciation accuracy: A reexamination. Language Learning 30, 271-287

Sheppard, C., Hayashi, C., and Ohmori, A. 2007. Factors Accounting for Attainment in Foreign Language Phonological Competence. International Congress of Phonetic Sciences 2007, 1597 - 1600, Saarbrucken, Germany.

Wayland, R. 1997. Non0native Production of Thai: Acoustic Measurements and Accentedness Ratings. Applied Linguistics 18, 345-373. 